\title{
Influence of Arrester Parameters on Overvoltage Characteristics on Protected Transformer
}

\section{Abugalia A $^{*}$}

Sitre General Electrical Company, University of Sirte, Libya

\begin{abstract}
Different protective devices types based on previous literature are discussed. Special attention is focused on metaloxide surge arresters, their non-linear characteristics, models, factors affects on protective characteristics, effect and behavior in working conditions. The paper presents the analysis of the influence of non-linear characteristic of protective metal-oxide arrester on the overvoltage shape appeared on the protected transformer. The characteristic of the arrester is approximated by power type function. As an example the overhead transmission line connected to transformer through a busbar is considered. The line is characterized by their surge impedance and travel time and the transformer by its surge impedance. The transformer is protected by protective device such as metal-oxide arrester connected in parallel with it. The system of equations describing the overvoltage transmission line, transformer and the protective device modeled by non-linear v-i characteristic, based on digital step-by-step solution is written. The computer modeling software is used to solve the equations and compute overvoltage's waveshape at transformer. The ( $v-i),(v-t)$, and $(i-t)$ characteristics obtained as the result of these computations are presented.
\end{abstract}

Keywords: Arrester parameters; Overvoltage; Transformer

\section{Introduction}

Transient overvoltage studies and calculation are very important for electrical power engineering either for economic design of electrical apparatus or operational reliability of the system. This phenomenon is caused mainly either by lightning strikes (lightning overvoltage) or switching operation (operation overvoltage). Lightning overvoltage's are caused either by direct strokes to the phase conductor (back flashover), or as a result of strokes to earth very closed to the line which produce induced lightning surges. The overvoltage by which substation insulation is stressed is a function of the line construction and the system configuration. In fact the configuration of the station itself has great influence if the traveling time of surges within the station is not negligible in relation to the front time of the surge.

Overvoltage induced by indirect lightning on overhead lines can cause damage either the power system or to the electronic control and management system. Moreover, due to its more frequent occurrence, indirect lightning constitute a more important cause of microinterruptions than direct strike. Their estimation is therefore crucial for the correct operation coordination of overhead lines and, as a consequence, has been the object of various studies since the early years of the century.

For the purpose of this paper, switching overvoltage's are of a type which can be simulated by a standard switching impulse, i.e. an periodical wave with a front duration of the order of hundreds microseconds and a tail duration in the order of thousand microseconds. They stress the various parts of insulation in about the same proportions as power frequency voltage, but are not negative and only one peak of either polarity is normally significant. This overvoltage's generally arise from, a) Line energization and re-energization, b) Fault and fault clearing, c) Load rejections, d) Switching of capacitive currents and of small moderate inductive currents. These overvoltages in cases are depended on the characteristics of the equipment, especially of the circuit breakers, transformers and shunt reactors. They may be generally reduced by suitable choice of those characteristics, i.e. in first case by using per-insertion resistors and in second case by using surge arrester connected between the circuit-breaker and the transformer.

\section{Surge Arresters}

Protection of generators, transformers, SF6 basses, transmission lines, and other devices against levels of overvoltages which could permanently destroy their non-self-restoring insulation, is done by a suitable design providing guard and ground wires, and using surge diverts or lightning arresters. The main purpose of surge arresters is to satisfy these three conditions: 1) Withstand continuity the powerfrequency voltage at the which it attended to operater, 2) Limit overvoltages on electric power systems by discharging transient energy in the form of current, 3) operate in the same environment as the protected equipment. These protective devices are designed and installed to limit the magnitudes of overvoltages against which they protect equipment. Therefore the total surge-arrester voltage during operation should not exceed on acceptable value. There rating is defined as the specified maximum permissible r.m.s value of power-frequency voltages between their terminals at which they are designed to operate connectedly. This voltage may be applied continuously to surge arresters without changing their operating characteristics. In addition to this defined capability, some types of surge arresters, especially for $300 \mathrm{kv}$ and above range of voltage system, can successfully withstand either, a) higher than rated voltages for a specified short duration, or b) a specified number of successive discharge. In either cases, a controlling factor in the selection of the surge arrester is its ability to interrupt follow current at its rated voltage as in the case of temporary overvoltages, exceeding its rated voltage. Practically there are two basic types of surge arresters, namely Silicon-Carbide surge arresters, and Metal-Oxide surge arresters.

${ }^{*}$ Corresponding author: Abugalia A, Sitre General Electrical Company, University of Sirte, Libya, Tel: +229 952608 17; E-mail: abugalia55@yahoo.com

Received October 25, 2018; Accepted December 23, 2018; Published December 30, 2018

Citation: Abugalia A (2018) Influence of Arrester Parameters on Overvoltage Characteristics on Protected Transformer. J Electr Electron Syst 7: 284. doi: 10.4172/2332-0796.1000284

Copyright: @ 2018 Abugalia A. This is an open-access article distributed under the terms of the Creative Commons Attribution License, which permits unrestricted use, distribution, and reproduction in any medium, provided the original author and source are credited. 


\section{Silicon-carbide surge arresters}

Silicon-Carbide surge arresters consist of a Silicon-Carbide resistor with a non-linear $\mathrm{v}-\mathrm{i}$ characteristic, in series with a spark gap. The spark gap connects the arrester to the system when the overvoltage exceeds the spark over voltage, and the resistor limits the follow current and enable to arrester to interrupt the current in the gap. A resistor element in series with the gap is not very high, typically $4 \mathrm{~cm}$, therefore many such elements are stocked together in a series connection to produce the desired sparkover voltage and non-linear resistance for a particular voltage level. To achieve reasonably uniform voltage distribution along the stack, parallel R-C grading networks are used [1]. Selecting a SiliconCarbide distribution arrester has traditionally been based on voltage rating, it means, the maximum voltage that can occur on unfaulted phase during single line-to-ground fault must not exceed the arrester's voltage rating [2-5]. Silicon-Carbide surge arresters are modeled as a non-linear resistance in series with a gap which has a constant sparkover voltage. This sparkover voltage depends on the steepness of the incoming wave. The volt-time characteristic of series gap for a Silicon-Carbide surge arrester raise with steep impulse voltages and depends more over on the polarity of the overvoltage. Therefor the protection behavior of SiliconCarbide surge arrester is mainly controlled by the behavior of the series gap for the fast rising voltage [2].

\section{Metal-oxide surge arrester}

In recent years Metal-Oxide surge arresters without gap replacing more and more the covenantal Silicon-Carbide surge arresters with series gap. The Metal-Oxide surge arrester has more non-linear voltage-current characteristic than Silicon-Carbide surge arrester. It means they are highly non-linear resistors, with an almost infinite slope in the normal-voltage region, and an almost horizontal slope in the overvoltage protection region. Additionally at fast rising voltage, the protective characteristic of the Metal-Oxide surge arrester is expected to be better, because the turn-on characteristic is not determined by series gap [1]. As a comparing point of view, the advantages of Metal-Oxide surge arrester over Silicon-Carbide surge arresters can be summarized as: 1) Extreme non-linearity (flatness) of V-I characteristics, 2) Elimination of the requirement for a series gap and associated gap sparkover voltage [2], 3) The absence of the gap means that under step overvoltage conditions there is no need to consider the volt-time gap sparkover characteristics, 4) Volume reduced by as much as 60 percent since gaps and grading components are eliminated, 5) Gapless arresters are much less prone to deterioration in performance due to high surface contamination because there is no gap sparkover consideration.

As protective device the primary function of Metal-Oxide surge arrester is to protect transmission line and distribution equipment from overvoltage and to absorb electrical energy resulting from the lightning or switching surges or temporary overvoltage [3].

Metal-Oxide surge arresters generally have the characteristics that its residual voltage rises for current impulse having more steep front than standard impulse current $(8 / 20 \mu \mathrm{s})$. Rising rate of residual voltage depends on the time to crest, peak value of the current and kinds of models. The laboratory tests prove that the Metal-Oxide surge arrester have very strong dynamic V-I characteristics for lightning and other fast-front surges. These characteristics become important in considering the insulation coordination and arrester location [4]. For example for G.I.S switchgear the insulation coordination must be designed more rationally, taking account of the protection performance of surge arresters. The arrester protective characteristic is the combination of its residual voltages for different current impulses.
For a good protection, the arrester characteristic should lie well below the equipment insulation withstand levels at all points. The protective level or voltage limiting characteristic of the completely gapless surge arresters is determined basically by, a) The maximum continues line to ground operating voltage $\mathrm{V}_{\mathrm{sS}}$, b) The non-linear parameter $\mathrm{b}$ from the crossover voltage $\mathrm{V}_{\mathrm{C}}$ to the coordinating lightning current discharge voltage $\mathrm{V}_{\mathrm{KA}}$.

\section{Modeling of Surge Arresters}

Since 1975 when the first practical application of Metal-Oxide surge arrester to real power system, a number of studies testes and publications describes many methods of MoA modeling. Summary of some models proposed and investigated in several previous literatures is discuses in the following paragraphs.

1. The Metal-Oxide surge arresters are highly non-linear resistor with infinite slop in the normal voltage region and horizontal slop in the overvoltage protection region. A simple model of this device with so-cold static model "characteristic" is shown in Figure 1.

According EMTP the non-linear resistance is represented by:

$$
\mathrm{i}=\mathrm{p}\left(\mathrm{V} / \mathrm{V}_{\text {ref }}\right)^{\mathrm{q}}
$$

where $\mathrm{p}$ and $\mathrm{V}_{\text {ref }}$ are constants $q$ is degree of non-linearity typically its value in the range of 20 to 30 . Because of difficulty to describe the entire region with one power function, then the voltage region has been divided into segments in the BPA EMTP, each one defined by its own power function [5]. This static characteristic can be changed to dynamic characteristic as adding a series inductance $L$, whose value may estimate once the arrester current is known from trail run [6]. The model for fast front currents surges with time to crest in the range of 0.5 to $10 \mu$ s is developed by Durbak [7] and simulated in EMTP as shown in Figure 2.

The main aid is to divide a single non-linear resistance into $\mathrm{m}$ parallel non-linear resistances, separated by low pass filters; in practical case two parallel non-linearities are sufficient. The $\mathrm{R}_{1}-\mathrm{L}_{1}$ elements is the low pass which filter separates two non-linear resistances defined by $\mathrm{i}_{\mathrm{o}}\left(\mathrm{v}_{\mathrm{o}}\right), \mathrm{i}_{1}\left(\mathrm{v}_{1}\right)$. The inductance $\mathrm{L}_{\mathrm{O}}$ represent the small but finite inductance associated with magnetic fields in the immediate vicinity of the surge arrester.

$R_{O}$ is used only to damp numerical oscillation and $C$ is the stray capacitance of surge arrester.

2. From experimental results a model of surge arrester block was developed by K. Feser [1] as shown in Figure 3.

This model consists two group of elements, one group connected in parallel follow the equivalent circuit of grain boundary of varistor and the second group of elements $\mathrm{R}_{3}$, $\mathrm{L}$ is refer to the Metal-Oxide grain.

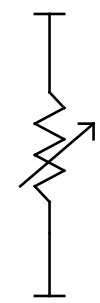

Figure 1: Simple model for static characteristic of MoA 


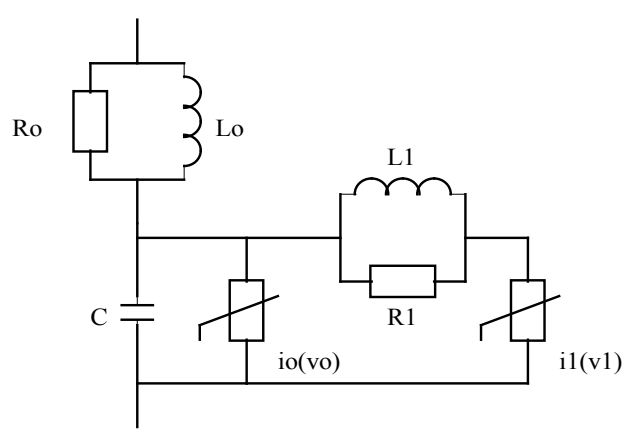

Figure 2: Complete model presented in EMTP.

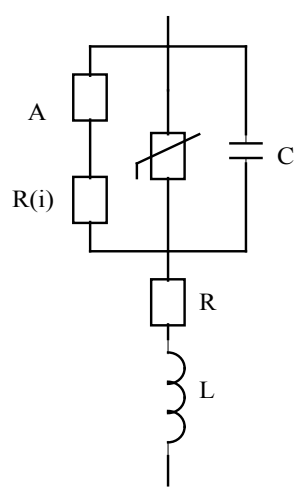

Figure 3: K. Feser model for surge arrester.

The characteristic of non-linear element in the first gr oup depends on the magnitude and the rapidity of change of varistor current and temperature. The turn-on element A can be evaluated from the results of the measurements obtained with the RLC-circuit. The non-linear resistance consists of the non-linear effect at the grain boundary and the linear resistance of the $\mathrm{ZnO}$-grain.

The turn-on element A reflects the dynamic charge distribution at the grain boundary. Its dynamic behavior depends on the voltage wave shape $(\mathrm{du} / \mathrm{dt}, \mathrm{U})$ and time constant $\tau$, and its characteristic given as a function of the current and current steepness $\mathrm{di} / \mathrm{dt}$ for the investigated ZnO-material composition.

The capacitance $\mathrm{C}$ of the arrester block depends on the applied transient. It may estimate "experimentally' about $0.8 \mathrm{nF}$ for the highest $\mathrm{di} / \mathrm{dt}$ and about $1.5 \mathrm{nF}$ for low voltage of $\mathrm{di} / \mathrm{dt}$.

Although this model gives an excellent agreement between the measurement and calculation results for the wide range of steepness of current impulse from rectangular current impulse with rise times of some ns to double exponential current with rise time of some ns, but practical use of this model is not easy because the evaluation of its elements values depends on many different parameters.

3. Anther frequency-dependent model of surge arrester is shown in Figure 4 which is the similar to the model simulated in EMTP and discussed above.

This model is developed by American Electric Power and General Electric and recommended by IEEE W.G. 3.4.11 in 1982 [8,9]. As an addition to discuss in paragraph 1 , in the case of slow-front surges, the filter $R_{1}-L_{1}$ has very little impedance and the $A_{O}$ and $A_{1}$ section of the model are essentially in parallel for fast-front surges the impedance of the $\mathrm{R}_{1}-\mathrm{L}_{1}$ filter becomes more significant, the result is that the arrester model generates at high voltage.

The author [4] gives an excellent simulation for discharging voltage for a different type of ABB arresters dealing with this model.

As general the last two models described above have many applications problems, one of them how to choose specific values of their parameters.

In this paper the example of MO characteristics obtained by the non-linear equivalent scheme is presented. The influence of parameter describing the non-linear voltage-current static characteristic of arrester is shown.

\section{Numerical Example}

\section{Surge arresters models and transmission line equations}

The Figure 5 shows the layout of transmission line connected to a transformer presented by wave impedance $Z_{T}$ through a cable. The transformer is protected with $\mathrm{ZnO}$ surge arrester placed in parallel with it.

According to Kirchhoff' law, the network can be simplified as in (Figure 6a-c) with the corresponding equations (1 to 7).

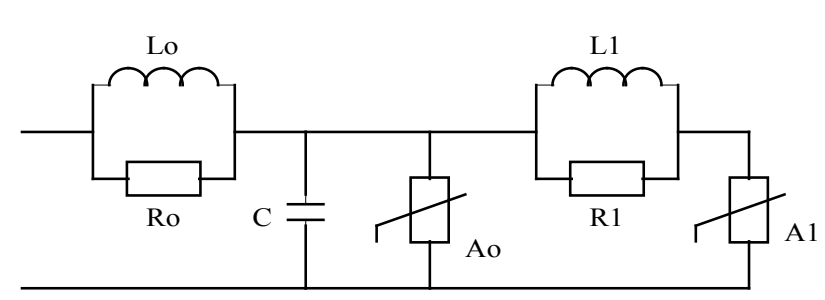

Figure 4: Recommended model of IEEE W. G.

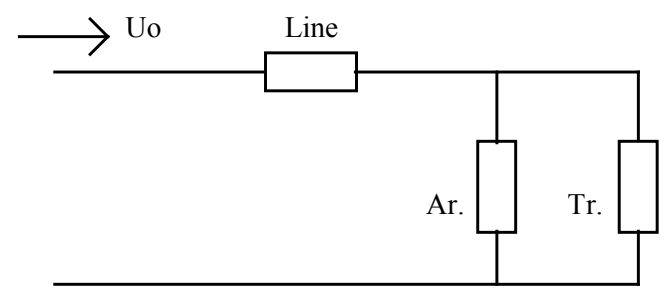

Figure 5: Layout of problem.

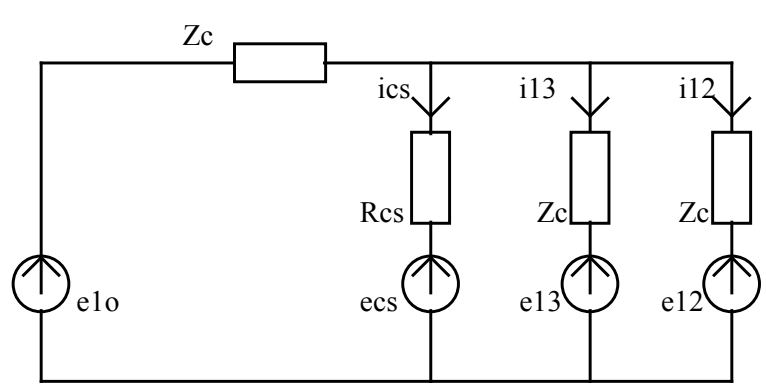

Figure 6a: Distribution of Voltage and Current. 


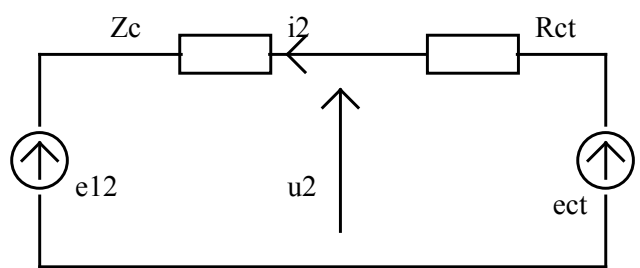

Figure 6b: distribution of voltage and current at transformer

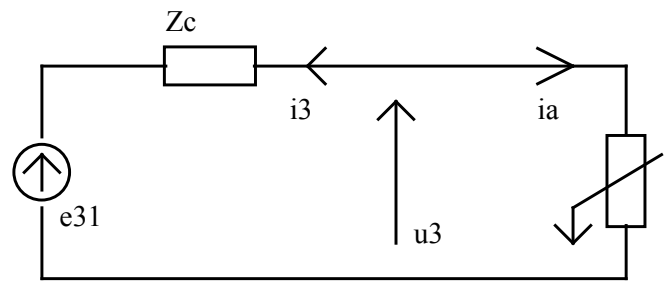

Figure 6c: distribution of voltage and current at arrester.

$$
\mathrm{e}_{10}=2 \mathrm{u}_{0}(\mathrm{k})
$$

$\mathrm{e}_{\mathrm{CS}}(\mathrm{k})=\mathrm{u}_{1}(\mathrm{k}-1)+\mathrm{R}_{\mathrm{CS}} \cdot \mathrm{i}_{\mathrm{CS}}(\mathrm{k}-1)$

$\mathrm{e}_{12}(\mathrm{k})=\mathrm{u}_{2}\left(\mathrm{k}-\mathrm{n}_{12}\right)+\mathrm{Z}_{\mathrm{c}} \cdot \mathrm{i}_{2}\left(\mathrm{k}-\mathrm{n}_{12}\right)$

$$
\begin{aligned}
& e_{13}(k)=u_{3}\left(k-n_{13}\right)+Z_{C} \cdot i_{3}\left(k-n_{13}\right) \\
& e_{21}(k)=u_{1}\left(k-n_{12}\right)+Z_{C} \cdot i_{12}\left(k-n_{12}\right)
\end{aligned}
$$

$$
\text { for } \mathrm{t}<\mathrm{o}
$$

where $\mathrm{u}_{1}(\mathrm{k})=\mathrm{u}_{2}(\mathrm{k})=\mathrm{u}_{3}(\mathrm{k})=0$

$$
\mathrm{i}_{12}(\mathrm{k})=\mathrm{i}_{13}(\mathrm{k})=\mathrm{i}_{2}(\mathrm{k})=\mathrm{i}_{3}(\mathrm{k})=0
$$

$\mathrm{n}_{12}=\mathrm{t} / \mathrm{n}, \quad \mathrm{n}_{13}=\mathrm{t} / \mathrm{n}$

The digital solution of these Kirchhoff equations of these schemes can be obtained as follows from Figure 6a:

$\mathrm{u}_{1}(\mathrm{k})=\frac{\mathrm{e}_{10}(\mathrm{k})+\mathrm{e}_{12}(\mathrm{k})+\mathrm{e}_{13}(\mathrm{k})+\left(\mathrm{Z}_{\mathrm{C}} / \mathrm{R}_{\mathrm{CS}}\right) \mathrm{e}_{\mathrm{CS}}(\mathrm{k})}{3+\left(\mathrm{Z}_{\mathrm{C}} / \mathrm{R}_{\mathrm{CS}}\right)}$

$\mathrm{i}_{12}(\mathrm{k})=\frac{1}{\mathrm{Z}_{\mathrm{C}}}\left[\mathrm{u}_{1}(\mathrm{k})-\mathrm{e}_{12}(\mathrm{k})\right]$

$\mathrm{i}_{13}(\mathrm{k})=\frac{1}{\mathrm{Z}_{\mathrm{C}}}\left[\mathrm{u}_{1}(\mathrm{k})-\mathrm{e}_{13}(\mathrm{k})\right]$

onstants.

$\mathrm{i}_{\mathrm{CS}}(\mathrm{k})=\frac{1}{\mathrm{Z}_{\mathrm{C}}}\left[\mathrm{u}_{1}(\mathrm{k})-\mathrm{e}_{\mathrm{CS}}(\mathrm{k})\right]$

From Figure 6b

$$
\begin{aligned}
& i_{2}(k)=\frac{e_{C T}(k)-e_{21}(k)}{\left(Z_{C}+R_{C T}\right)} \\
& u_{2}(k)=e_{21}(k)+Z_{C} i_{2}(k)
\end{aligned}
$$

The non-linear Voltage-Time characteristic of arrester may describe by $\mathrm{u}=\mathrm{A} \mathrm{i}^{\mathrm{b}}$ [1], where $b$ is the degree of non-linearity and $A$ is constants. Then from Figure $6 \mathrm{c}$ :

$$
\begin{aligned}
& \mathrm{u}_{3}(\mathrm{k})=\mathrm{e}_{31}(\mathrm{k})+\mathrm{Z}_{\mathrm{C}} \mathrm{i}_{3}(\mathrm{k}) \\
& \mathrm{u}_{3}(\mathrm{k})=\mathrm{A} \cdot \mathrm{i}_{\mathrm{a}}^{\mathrm{b}}(\mathrm{k}) \\
& i_{3}(k)=-i_{a}(k)
\end{aligned}
$$

where $\mathrm{Z}_{\mathrm{C}}$ surge impedance of line in $\Omega$

$$
\begin{aligned}
& \mathrm{C}_{\mathrm{S}} \text { substation input capacity in } \mathrm{pF} \\
& \mathrm{C}_{\mathrm{T}} \text { transformer input capacity in } \mathrm{pF}
\end{aligned}
$$

\section{Data approximation}

To test the influence of the parameter of surge arrester, overvoltage wave is applied on the system, Eq $(17,18)$. This wave consists of two parts:

a). linear part $\mathrm{u}(\mathrm{t})=\frac{\mathrm{U}_{\max }}{\mathrm{T}_{\mathrm{f}}}$ for $0 \leq \mathrm{t} \leq \mathrm{T}_{\mathrm{f}}(17)$

b). exponential part $U(t)=U_{m} \exp \left\lfloor-\alpha\left(t-t_{f}\right)\right]$

for $\mathrm{t} \geq \mathrm{T}_{\mathrm{f}}(18)$

$$
\mathrm{a}=\frac{\ln 2}{\mathrm{~T}_{\mathrm{p}}-\mathrm{T}_{\mathrm{f}}}
$$

Data is carried out for overhead line with $220 \mathrm{kv}$ rated voltage of $400 \Omega$ wave impedance. The distance between the transformer and connection point is $30 \mathrm{~m}$, the distance between transformer and arrester $15 \mathrm{~m}$. Maximal voltage $550 \mathrm{kv}$. $0.5 / 50 \mu$ s wave propagates with velocity $300 \mathrm{~m} / \mu \mathrm{s} . \mathrm{C}_{\mathrm{s}}=1600 \mathrm{pF}, \mathrm{C}_{\mathrm{T}}=1200 \mathrm{pF}$.

By preparing a computer program based in FORTRAN to solving all these equations and using Newton-Raphsen, (iteration method) to solve non-linear equation, the voltages and currents at transformer and arrester are computed.

\section{Results}

The results obtained are presented as follows:

1) The influence of parameter describing the nonlinearity of V-I characteristic on the voltage shape on the transformer is shown in Figure 7.

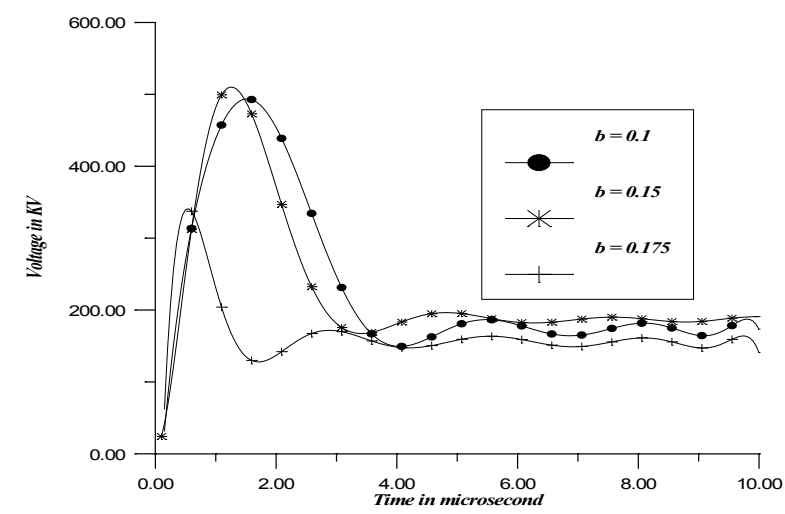

Figure 7: Voltage at transformer with different values of parameter. 


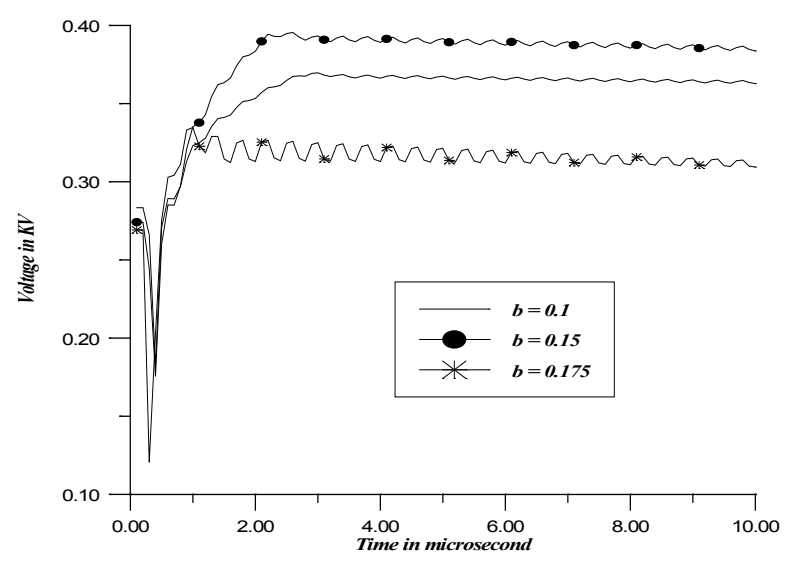

Figure 8: Voltage at arrester with different values of parameter.

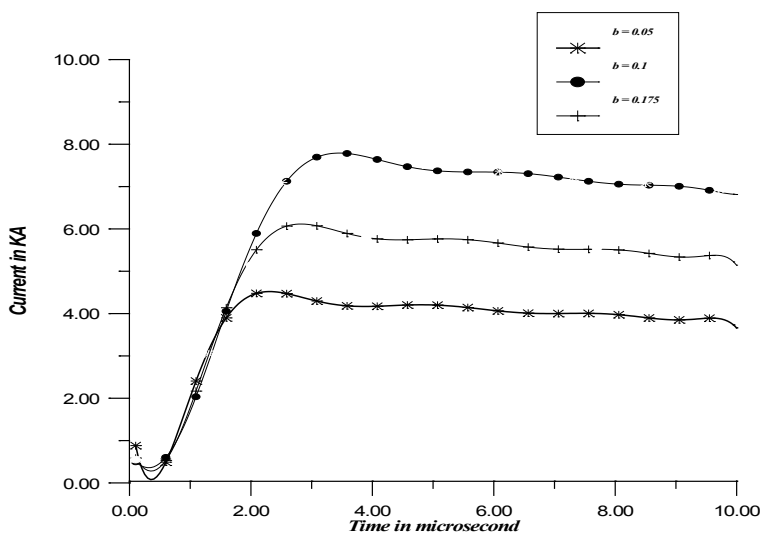

Figure 9: Current at arrester for different values of parameter.

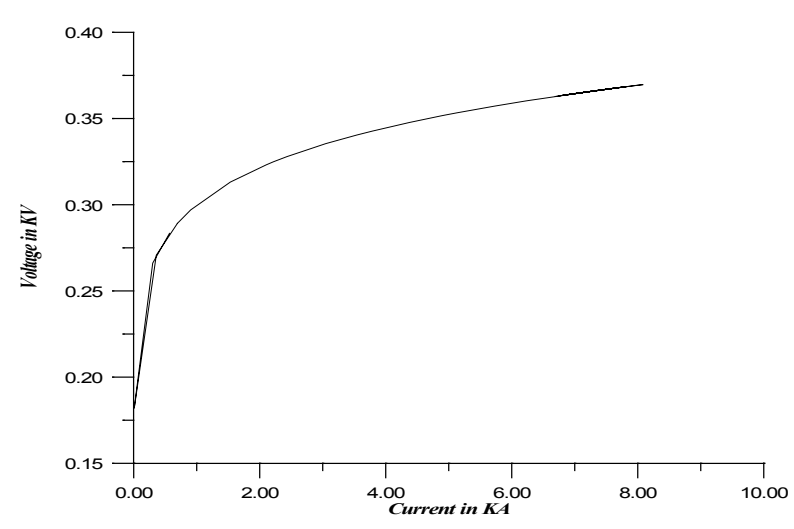

Figure 10: Voltage-Current characteristic for $b=0.1$.
2) The same influence on the voltage shape arising on the arrester is shown in Figure 8.

3) The same influence on arrester current is given in the Figure 9.

4) The voltage-current characteristic on the arrester is shown in Figure 10.

\section{Conclusion}

From the graphs the following notice can be written:

- It is very important to choose the parameters of non-linear characteristic of protective devices i.e. the degree of non-linearity. Figures 7-10 are a good example to show the effect of the changing of this parameter on the voltage and current characteristic either at transformer or arrester.

- The action of surge arresters to the voltage surge presented to transformer should prevent the surge magnitude exceeding the protective level. This is clear in figures and they show the decreasing the peak value of overvoltage wave presented at transformer.

For all of these observations, it is clear that the using of surge arrester is very important and useful to protect the equipment's such transformer, if the good study and experiment to choose it's characteristic is done.

\section{References}

1. Schmidt W, Meppelink J, Richter B, Feser K, Kehl L (1989) Behavior of MOSurge Arrester Blocks to Fast Transient. IEEE T Power Deliv 4: 292-300.

2. Kershow SS, Gaibrois GL, Stump KB (1989) Applying Metal-Oxide Surge Arresters on Distribution Systenm. IEEE T Power Deliv 4: 301-307.

3. Shirakawa S, Endo F, Kitajima H, Kobayashi S, Kurita K (1988) Maintenance of surge Arrester by a Portable Arrester leakage Current Detector. IEEE T Power Deliv 3: 998-1003.

4. Bajorek J, Knott M, Wyderka S (1992) Efficiency of Zno Arrester Models in Digital Simulation of Lightning overvoltages. ICLP Berlin, Germany, Pp: 265270

5. Aternative Transient Program (Atp), Role Book, Canadian/American EMTP User Group 1987/92.

6. Tominaga S, Azumi K, Shibuya Y, Imataki M, Fujiwara Y (1979) Protective Performance of Metal Oxide Surge Arrester Basedon the Dynamic V-I characteristics. IEEE Trans Power App Syst PAS-98: 1860-1871.

7. Durbak DW (1985) Zinc-Oxide Arrester Model for Fast Surges. EMTP Newsletter 5: 1-9.

8. IEEE Working Group (1992) Modeling of Metal Oxide Surge Arresters. IEEE T Power Deliv 7: 1.

9. Wlodek R, Bajorke J (1990) Examples of Overvoltage Calculations in Powe Systems (in Polish) Ed. AGH Krakow. 